\title{
Sistem Penyelenggaraan Makanan, Preferensi Menu dan Tingkat Kepuasan di PPLP Jawa Barat
}

\author{
Aditya Sagara Putra ${ }^{1}$, Putri Ronitawati*2 ${ }^{2}$, Laras Sitoayu ${ }^{2}$, Rachmanida Nuzrina $^{2}$, Vitria Melani ${ }^{1}$ \\ ${ }^{1}$ Program Studi Ilmu Gizi, Fakultas Ilmu-ilmu Kesehatan, Universitas Esa Unggul, Jakarta, Indonesia \\ ${ }^{2}$ Program Studi Pendidikan Profesi Dietisien, Fakultas Ilmu-ilmu Kesehatan, Universitas Esa Unggul, Jakarta, \\ Indonesia
}

Author's Email Correspondence (*): putri.ronitawati@esaunggul.ac.id

\begin{abstract}
Abstrak
Preferensi konsumen menggambarkan suatu kecenderungan perilaku konsumen pada pola konsumsi dan daya tarik mereka terhadap nilai-nilai yang disediakan oleh pihak penyelenggara makanan. Penelitian ini bertujuan untuk mengetahui analisa penyelenggaraan makanan, hubungan preferensi menu dengan tingkat kepuasan makanan di Pusat Pendidikan Latihan Pelajar (PPLP) Jawa Barat. Jenis penelitian ini adalah penelitian Cross Sectional dengan metode survey observational. Sampel sebanyak 81 responden dengan menggunakan teknik pengambilan sampel purposive sampling. Analisa statistik menggunakan Uji Korelasi Pearson. Penelitan ini menunjukkan bahwa preferensi menu memiliki hubungan dengan tingkat kepuasan makanan $(p=0.000)$, tidak ada hubungan antara variasi menu dengan tingkat kepuasan makanan $(p=0.630)$, penampilan makanan memiliki hubungan dengan tingkat kepuasan makanan $(p=0.000)$, dan rasa makanan memiliki hubungan dengan tingkat kepuasan makanan $(p=0.000)$. Semakin pihak institusi memperhatikan preferensi menu atlet, maka atlet akan merasa puas dengan penyelenggaraan makanan yang disediakan institusi
\end{abstract}

Kata Kunci: Penyelenggaraan Makanan; Preferensi menu; Tingkat Kepuasan; Atlet

How to Cite:

Putra, A., Ronitawati, P., Sitoayu, L., Nuzrina, R., \& Melani, V. (2021). Sistem Penyelenggaraan Makanan, Preferensi Menu dan Tingkat Kepuasan di PPLP Jawa Barat. Ghidza: Jurnal Gizi Dan Kesehatan, 5(1), 54 - 62. https://doi.org/10.22487/ghidza.v5i1.152

Published by:

Tadulako University

Address:

Soekarno Hatta KM 9. Kota Palu, Sulawesi Tengah, Indonesia.

Phone: +628525357076

Email: ghidzajurnal@gmail.com
Article history :

Received : 09102020

Received in revised form : 02072021

Accepted : 03072021

Available online 07072021 


\begin{abstract}
Consumer preferences describe a trend of consumer behavior in consumption patterns and their attractiveness to the values provided by the food organizer. This study aims to determine the analysis of food management, the relationship between menu preferences and the level of food satisfaction at the West Java Student Training Center (PPLP). This type of research is a cross sectional study with an observational survey method with a population of 123 athletes and a sample size of 81 respondents using purposive sampling technique. Data were analyzed univariate and bivariate using statistical testing Pearson Product Correlation Test with a confidence level of 95\% ( $p<0.05)$. This research shows that menu preferences have a relationship with the level of food satisfaction $(p=0.000)$, there is no relationship between menu variations and the level of food satisfaction $(p=0.630)$, food appearance has a relationship with the level of food satisfaction $(p=0.000)$, and the taste of food has a relationship with the level of food satisfaction $(p=0.000)$. The more the institution pays attention to athletes' menu preferences, the athletes will be satisfied with the food management provided by the institution.
\end{abstract}

Keywords: Food Service; Food Satisfaction Level; Menu Preference; Athlete

\title{
I. PENDAHULUAN
}

Dalam meningkatkan prestasi atlet indonesia kedepan, dirasakan perlu untuk memperbaiki dan menyempurnakan sistem pembinaan dan pelatihan olahraga. Disamping itu pemenuhan asupan gizi dan pengaturan makan merupakan kebutuhan dasar bagi atlet (Kemenkes RI , 2013). Atlet memerlukan pengaturan makan yang tepat untuk memenuhi kebutuhan zat gizinya. Implementasi penyelenggaraan makanan pada club- club olahraga yang didasarkan pada kebutuhan atlet menjadi sangat penting dalam rangka upaya meningkatkan dan menjaga prestasi. Pemberian makanan harus memperhatikan jenis kelamin atlet, umur, berat badan, serta jenis olahraga. Selain itu, pemberian makanan juga harus memperhatikan periodisasi latihan, masa kompetisi, dan masa pemulihan (Hafidz Asy'ari Hasbullah et al., 2017). Keberhasilan suatu penyelenggaraan makanan pada masa pemusatan latihan dan masa pertandingan dapat dicapai bila penyelenggaraan makanan dipandang suatu program yang utuh dikelola secara professional, makanan yang memenuhi syarat gizi seimbang memegang peranan vital bila atlet ingin mendapatkan prestasi maksimal. Bahkan dengan kombinasi yang baik antara atlet yang berbakat, teknik latihan dan pelatih terbaik, namun makanan yang tidak memenuhi syarat dan gizi tidak seimbang tidak mungkin atlet dapat berprestasi secara maksimal (Syafrizar \& Welis, 2009).

Penyelenggaraan makanan memiliki tujuan agar konsumen merasa puas. Jaminan mutu merupakan prioritas utama untuk meningkatkan daya terima para atlet mengonsumsi makanan sehingga para atlet merasa puas dengan makanan yang disediakan oleh pusat pelatihan (Kustiyoasih et al., 2017). Preferensi konsumen menggambarkan suatu kecenderungan perilaku konsumen pada pola konsumsi dan daya tarik mereka terhadap nilai-nilai yang disediakan oleh pihak penyelenggara makanan. Preferensi juga dapat diartikan sebagai tingkat kesukaan seseorang atau penilaian seseorang terhadap suatu makanan atau produk yang disajikan. Agar terciptanya kepuasan yang dirasakan oleh konsumen maka perlu diperhatikan juga mengenai preferensi konsumen terhadap makanan yang di sediakan oleh tempat penyelenggara makanan, khususnya untuk atlet. Atlet sangat memerlukan asupan makanan \& zat gizi 
yang cukup untuk kebutuhan latihan sehari-hari, jika pihak penyelenggara makanan tidak melihat preferensi menu pada atlet maka atlet akan merasa tidak puas dan akan mengonsumsi makanan lain dari luar.

Berdasarkan hasil penelitian penyelenggaraan makanan di Pusat Pendidikan dan Latihan Pelajar (PPLP) Dinas Pendidikan Pemuda dan Olahraga Makassar terhadap tingkat kepuasan, bahwa proses penyelenggaraan makanan pada umumnya dilakukan dengan baik tetapi tidak dilakukan pemantauan dan evaluasi. Siklus menu di institusi tersebut adalah 7 hari yang terdiri dari 60 menu. Menu dengan jumlah energi terbesar pada hari Kamis di 2.864 kkal, sedangkan yang paling sedikit pada hari Senin, 2.432 kkal. Tingkat kepuasan rata-rata atlet sepakbola dan sepak takraw, masing-masing 66,56\% dan 62\%, yang termasuk dalam kategori "tidak puas". Atlet ke tingkat kepuasan keseluruhan cabang seni bela diri menu untuk 60,67\% (kategori "Tidak Puas"), dari gulat pada 89,65\% (kategori "Puas"), dan tinju di 80,19\% (kategori "puas") (Nurdianty et al., 2012). Terdapat permasalahan penyelenggaraan makanan di PPLP Jawa barat yaitu pada variasi menu yang ada, atlet mengeluhkan mengenai variasi menu sehingga atlet merasa bosan karena selalu dilakukan pengulangan pada bahan makanan di hari yang sama. Hal tersebut menyebabkan atlet terkadang lebih memilih membeli makanan dari luar dibandingkan menyantap makanan yang disediakan. Lalu tidak dibedakkannya makanan berdasarkan intensitas olahraga dan makanan untuk latihan, pertandingan dan pemulihan itu juga merupakan suatu masalah pada penyelenggaraan makanan karena setiap olahraga memiliki kebutuhan zat gizi yang berbeda-beda.

Berdasarkan latar belakang yang telah diuraikan, maka peneliti tertarik untuk meneliti mengenai analisa penyelenggaraan makanan, hubungan preferensi menu dengan tingkat kepuasan makanan di Pusat Pendidikan Latihan Pelajar (PPLP) Jawa Barat.

\section{METHOD}

Penelitian ini dilakukan dengan tujuan mendeskripsikan analisis penyelenggaraan makanan dan menganalisis hubungan preferensi menu dengan tingkat kepuasan makanan pada atlet di Pusat Pendidikan dan Latihan Pelajar Jawa Barat. Peneliti menggunakan desain cross sectional dengan metode survey observational. Populasi penelitian ini sebesar 124 orang atlet PPLP Jawa Barat dengan sampel penelitiannya sebesar 81 orang dengan menggunakan teknik purposive sampling, yang seluruhnya telah memenuhi persyaratan insklusi penelitian. Kriteria inklusi pada penelitian ini yaitu : Atlet yang berumur 13-18 tahun dan terdaftar sebagai atlet binaan di PPLP Jawa Barat dan kriteria eksklusinya yaitu atlet yang sedang dalam persiapan masuk perguruan tinggi. Pengambilan data dilakukan untuk memperoleh informasi mengenai karakteristik atlet, preferensi menu atlet dan tingkat kepuasan atlet terhadap penyelenggaraan makanan di PPLP Jawa Barat. Semua data yang ditelah diambil akan dianalisa untuk mengetahui hubungan antar variabel dengan menggunakan pengujian statistik korelasi pearson product dengan bantuan software SPSS 22. Penelitian ini sudah disetujui oleh dewan penegakan kode etik universitas esa unggul dengan no etik 0103-19.566/DPKE-KEP/FINAL-EA/UEU/I/2020 


\section{HASIL}

Penyelenggaraan makanan di asrama atlet PPLP Jawa Barat dilakukan dengan menggunakan sistem full out sourcing yang penyelenggaraan makanannya diborongkan penuh kepada pengusaha jasa boga atau catering termasuk sarana prasarana untuk kebutuhan pengolahan dan distribusi, pihak asrama hanya menyediakan tempat khusus untuk makan atlet. Tenaga pelaksana penyelenggaraan makanan di PPLP Jawa Barat berjumlah 7 orang, satu orang supervisor, 3 orang yang bertugas untuk pengolahan makanan, 2 orang bertugas untuk pendistribusian makanan dari tempat catering ke asrama atlet dan 1 orang bertugas sebagai pramusaji dan pembiayaan pada setiap atlet untuk kebutuhan makannya yaitu Rp.80.000,00 untuk satu hari makan. Menu yang digunakan di PPLP Jawa Barat ini menggunakan siklus menu 10 hari yang terdiri dari makanan pokok, lauk hewani, lauk nabati, sayur, snack, buah dan susu yang dilaksanakan selama 1 tahun. Tidak terdapat pemesanan bahan makanan oleh catering PPLP Jawa Barat karena segala pembelian bahan makanan dilakukan langsung oleh petugas masak dengan cara pembelian langsung ke pasar, tidak ada proses penerimaan saat bahan makanan sampai di catering sehingga tidak ada pengecekan ulang pada spesifikasi bahan makanan, penyimpanan bahan makanan dibedakan menjadi bahan kering dan bahan basah yang prinsp penyimpanannya sudah menerapkan FIFO (First In First Out) dan FEFO (First Expired First Out), bahan yang akan dilakukan pengolahan dilakukan berdasarkan jenis bahan makanannya dan diolah tiga jam sebelum waktu makan dan proses pendistribusian makanan menggunakan cara desentralisasi karena tempat pengolahan makanan yang terpisah dengan asrama atlet. Ketika makanan sampai, makanan langsung dibawa menuju ruang makan atlet dan proses pengambilan makan dengan cara prasmanan sehingga atlet dapat menentukan sendiri porsi makannya tapi untuk pengambilan makan tetap diawasi oleh petugas pramusaji.

Hasil penelitian menunjukkan bahwa sebagian besar atlet masuk dalam kategori remaja awal, dengan jumlah 46 orang (56.8\%), dan sebagian besar atlet berjenis kelamin laki-laki sebanyak 46 orang (56.8\%). Rata-rata umur atlet di PPLP Jawa barat yaitu 16.19 \pm 1.28 dengan umur atlet yang paling muda berumur 13 tahun dan yang paling tua berumur 18 tahun (Tabel 1). Pada penilaian variasi menu, sebagian besar atlet memberikan penilaian sedang dengan jumlah 64 orang $(79 \%)$ pada menu makanan yang disajikan di PPLP Jawa Barat, dengan rata-rata atlet memberikan skor 18.81 \pm 2.44 dengan skor terkecil yaitu 11 dan yang paling tinggi dengan skor 25. Pada penilaian penampilan makanan yang ditunjukkan pada Tabel 1, sebanyak 61 orang atlet memberikan penilaian sedang $(75.3 \%)$ pada penampilan makanan yang ada di PPLP jawa Barat dengan rata-rata skor 94.79 \pm 9.69 dengan penilaian terkecil dengan skor 62 dan paling tinggi yaitu 120. Berdasarkan Tabel 1, sebanyak 65 orang $(80.2 \%)$ memberikan penilaian sedang pada rasa makanan di PPLP Jawa barat dengan skor rata-rata rasa makanan adalah 95.30 \pm 8.16 dengan pemberian skor terkecil yaitu 72 dan skor paling tinggi yaitu 120. Penilaian pada tingkat kepuasan makanan di PPLP jawa Barat yang di tunjukkan pada tabel 1, sebagian besar atlet memberikan penilaian sedang sebanyak 79 atlet (97.5) dengan rata-rata skor penilaian tingkat kepuasan adalah $101.41 \pm 15.64$ dengan skor terkecil yaitu 60 dan tertinggi yaitu 130.

Tabel 2 menunjukkan bahwa berdasarkan hasil analisis menggunakan uji korelasi pearson product yang dilakukan terhadap variabel preferensi menu, variasi menu, penampilan makanan dan rasa makanan 
didapatkan hasil yaitu ada hubungan antara preferensi menu dan tingkat kepuasan makanan $(\mathrm{p}=0.000)$ dengan arah positif, tidak ada hubungan antara variasi menu dan tingkat kepuasan makanan $(\mathrm{p}=0.630)$ yang menunjukkan arah negatif, ada hubungan antara penampilan makanan dan tingkat kepuasan (0.000) yang hubungannya memiliki arah positif dan ada hubungan antara rasa makanan dan tingkat kepuasan (0.000) yang menunjukkan arah positif.

Tabel 1. Karakteristik responden

\begin{tabular}{lc}
\hline \multicolumn{1}{c}{ Variabel } & Jumlah (\%) \\
\hline Umur & \\
\hline Remaja awal (13-16 tahun) & $46(56.8)$ \\
Remaja akhir (17-25 tahun) & $35(43.2)$ \\
\hline Jenis kelamin & $46(56.8)$ \\
\hline Laki-laki & $35(43.2)$ \\
\hline Perempuan & \\
\hline
\end{tabular}

Tabel 2. Hubungan preferensi menu dengan tingkat kepuasan

\begin{tabular}{ccc|}
\hline Variabel & $\mathbf{r}$ & Tk.Kepuasan \\
\cline { 3 - 3 } & & Pvalue \\
Preferensi Menu & 0.586 & $0.000^{*}$ \\
Variasi Menu & -0.054 & 0.630 \\
Penampilan Makanan & 0.556 & $0.000^{*}$ \\
Rasa Makanan & 0.612 & $0.000^{*}$ \\
\hline
\end{tabular}

*Ket. signifikan apabila p value $\leq 0.05$

\section{PEMBAHASAN}

Hubungan antara variabel preferensi menu dengan tingkat kepuasan diperoleh $\mathrm{p}$ value $\leq 0.05$ yaitu 0.01 dengan nilai $r=0.586$ yang artinya ada hubungan yang signifikan antara preferensi menu dengan tingkat kepuasan di PPLP Jawa Barat dan memiliki arah positif dengan hubungan yang kuat, dengan demikian semakin baik penilaian preferensi menu maka semakin baik pula tingkat kepuasan makanan di PPLP Jawa Barat. Hal ini berbanding terbalik dengan penelitian Aruben et al (2017) yang menyatakan tidak ada hubungan antara preferensi menu dengan tingkat kepuasan. Menurut Febrianti (2009), preferensi dipengaruhi oleh waktu dan kondisi seperti apa saat makanan itu dihidangkan, dilihat dari keadaan lapar seseorang, perasaan dan saat terakhir seseorang mengkonsumsi makanan, suatu makanan tidak akan disukai jika belum pernah dicoba dan seseorang tidak akan mencoba makanan tersebut berulang kali jika makanan tersebut membosankan. Perlu adanya pergantian siklus menu setelah menu tersebut dilaksanakan selama 6 bulan dengan memperhatikan kejenuhan dari konsumen (Rotua \& Siregar, 2014). Variasi makanan yang baik akan membuat lebih banyak konsumen yang merasa puas dan meminimalkan sisa makanan yang dihasilkan (Damayanti, 2014). Pada penilaian preferensi menu pihak institusi kurang memperhatikan mengenai aspek preferensi terhadap menu yang disediakan. Makanan yang disediakan terlalu sering dilakukan dengan menggunakan bahan makanan yang sama, terlebih kadang-kadang pihak penyelenggara memberikan makanan yang sama dengan hari sebelumnya. Hal tersebut jika di lakukan berkali-kali maka akan menimbulkan rasa bosan pada atlet. Perlu diadakan survey tertulis yang dilakukan oleh pihak institusi untuk melihat penilaian atlet terhadap makanan yang disajikan, karena penilaian diadakan untuk melihat apakah penyelengaraan makanan oleh pihak institusi sudah tepat 
sasaran sehingga pihak institusi bisa mengevaluasi kekurangan yang dilihat dari penilaian tersebut agar terciptanya kepuasan dari atlet pada makanan yang disajikan.

Hubungan antara variabel variasi menu dengan tingkat kepuasan diperoleh $\mathrm{p}$ value $>0.05$ yaitu 0.630 dengan nilai $r=-0.054$ yang artinya variabel tidak ada hubungan yang signifikan antara variasi menu dengan tingkat kepuasan di PPLP Jawa Barat dan memiliki arah negatif, dengan demikian meskipun variasi menu telah diselenggarakan dengan baik tetapi belum tentu tingkat kepuasan atlet terhadap suatu makanan akan menjadi baik. Hal ini sejalan dengan penelitian yang dilakukan oleh Wahyunani (2017) tidak ada hubungan yang signifikan berdasarkan analisis statistik antara variasi menu dengan tingkat kepuasan, menurutnya menu makanan dikatakan bervariasi bila tidak terjadi penggunaan hidangan yang sama dalam satu siklus menu dan tidak terjadi metode yang sama dalam satu kali makan dan walaupun konsumen menyatakan puas tidak berarti menghabiskan makanan yang disajikan. Menurut penelitian Purba et al (2013) dan Tanuwijaya (2019) yang menyatakan ada hubungan antara variasi menu dengan tingkat kepuasan, variasi menu memerlukan kombinasi bahan-bahan makanan yang bermacammacam yang bertujuan untuk memuaskan konsumen. Variasi makanan yang ada di tempat penyelenggaraan makanan institusi berpengaruh terhadap kepuasan konsumen, karena saat makanan yang disajikan kurang bervariasi maka akan meyebabkan konsumen tidak berselera untuk mengonsumsinya (Nareswara, 2017). Variasi menu di PPLP Jawa Barat kurang baik dikarenakan pemilihan bahan makanan lauk hewani, nabati dan sayurnya tidak diperhitungkan secara terperinci, sebaiknya bahan makanan sama yang sudah dimasak di pagi hari tidak dimasak juga pada waktu makan lainnya, meskipun cara pemasakannya berbeda namun hal tersebut akan menimbulkan kejenuhan pada konsumen yang memakannya. Atlet yang berada di PPLP dinilai bosan terhadap menu yang disajikan, hal ini ditunjukkan dengan atlet yang sering kali memesan makanan melalui aplikasi online meskipun sudah menyantap makanan yang disediakan pihak institusi.

Hubungan antara variabel penampilan makanan dengan tingkat kepuasan diperoleh $p$ value $\leq 0.05$ yaitu 0.01 dengan nilai $r=0.556$ yang artinya terdapat hubungan yang signifikan antara penampilan makanan dengan tingkat kepuasan di PPLP Jawa Barat dan memiliki arah positif dengan hubungan kuat. Hal ini menunjukkan semakin baik penampilan makanan yang disajikan maka akan semakin baik juga tingkat kepuasan atlet pada makanan yang disediakan oleh PPLP Jawa Barat. Hal ini sejalan dengan penelitian yang dilakukan oleh Nareswara (2017) dan Lumbantoruan (2012), bahwa ada hubungan yang signifikan antara penampilan makanan dengan sisa makanan. Menurut Nareswara (2017), ketidakpuasan konsumen terhadap penampilan makanan meliputi: warna, bentuk, porsi, tekstur, dan penyajian makanan. Penampilan makanan merupakan faktor utama kepuasan konsumen. Penampilan makanan adalah faktor mutu yang sangat mempengaruhi suatu produk pangan, semakin banyak variasi antara semua faktor maka penampilan makanan semakin baik. Porsi makanan akan mempengaruhi daya tarik dari konsumen karena tiap-tiap konsumen memiliki besar porsi makanan yang berbeda dalam setiap aktivitas makannya. Besar porsi akan mempengaruhi penampilan makanan, jika terlalu besar atau terlalu kecil penampilan makanan jadi tidak terlalu menarik (Agustina, 2016). Penampilan makanan yang disajikan oleh catering PPLP Jawa Barat dinilai sudah baik namun masih ada kekurangan seperti adanya penilaian buruk terhadap 
warna makanan yang disajikan oleh pihak institusi. Warna merupakan aspek penting dalam penilaian penampilan makanan, semakin menarik variasi warna pada hidangan akan meningkatkan selera makan dan rasa puas pada konsumen, terlebih penilaian atlet di PPLP terhadap olahan sayur yang disediakan.

Hubungan antara variabel rasa makanan dengan tingkat kepuasan diperoleh $p$ value $\leq 0.05$ yaitu 0.01 dengan nilai $r=0.612$ yang artinya terdapat hubungan yang signifikan antara rasa makanan dengan tingkat kepuasan di PPLP Jawa Barat dan memiliki arah positif dengan hubungan kuat. Semakin baik rasa dari makanan yang disajikan maka akan semakin baik pula tingkat kepuasan atlet pada makanan yang disediakan oleh PPLP Jawa Barat. Hal ini sejalan dengan penelitian Juariah (2007), bahwa ada hubungan yang signifikan antara cita rasa dengan sisa makanan. Makanan yang memiliki cita rasa tinggi adalah makanan yang disajikan dengan menarik dan berbau sedap, serta memberikan rasa yang sedap sehingga memuaskan bagi yang menyantapnya (Moehyi, 1992). Menurut Agustina (2016), Aroma makanan adalah faktor penting untuk melakukan penilaian rasa makanan, dari aroma inilah akan timbul selera makan. Selera makan akan bertambah apabila terdapat variasi aroma pada makanan. Rasa makanan adalah aspek penilaian makanan yang sukar untuk dinilai secara akurat jika dibandingkan dengan tekstur dan warna makanan. Rasa makanan sangat bersifat subjektif, karena penilaiannya tergantung konsumen yang mengkonsumsinya. Beberapa atlet di PPLP memberikan nilai yang cukup rendah pada kesegaran buah dan bumbu sayur. Penilaian bumbu pada sayur sangat kurang dikarenakan rasanya terlalu hambar sehingga sayur tidak enak dimakan serta aroma bumbu pada sayur yang kurang tercium, dikarenakan aroma merupakan faktor penting untuk meningkatkan selera makan.

\section{KESIMPULAN}

Pada penelitian ini didapatkan hasil bahwa penilaian atlet pada preferensi menu dan tingkat kepuasan sudah dinilai baik meskipun terdapat beberapa atlet yang memberikan penilaian sebaliknya. Terdapat hubungan yang signifikan antara preferensi menu dengan tingkat kepuasan makanan, terdapat hubungan juga mengenai penampilan makanan dengan tingkat kepuasan makanan serta terdapat hubungan antara rasa makanan dengan tingkat kepuasan makanan. Namun tidak terdapat hubungan yang signifikan antara variasi menu dengan tingkat kepuasan makanan. Maka dapat disimpulkan bahwa semakin tinggi penilaian atlet pada setiap aspek preferensi menu maka hal tersebut akan memicu kepuasan atlet terhadap makanan yang disajikan di PPLP Jawa Barat.

\section{UCAPAN TERIMA KASIH}

Terima kasih kepada pihak PPLP Jawa Barat yang telah mengizinkan untuk melakukan penelitian dan mendukung hingga penelitian selesai dilaksanakan. Terima kasih juga saya ucapkan kepada Ibu Putri Ronitawati dan Ibu Laras Sitoayu selaku pembimbing skripsi saya, sehingga skripsi ini bisa selesai dengan semestinya. Dan terakhir terima kasih kepada teman dan keluarga yang selalu mendukung dalam proses penyelesaian skripsi ini. 


\section{DAFTAR PUSTAKA}

Agustina, F., (2016). Hubungan Antara Daya Terima Makanan dengan Tingkat Kepuasan Pelayanan Gizi Pasien Hipertensi Rawat Inap di RSUP dr Soeradji Tirtonegoro Klaten. Universitas Muhammadiyah Surakarta

Aruben, R., Azzahra, S. K., \& Suyatno. (2017). Hubungan Karakteristik Narapidana, Preferensi Penampilan, Rasa, dan Menu Makanan dengan Sisa Makanan. Jurnal Kesehatan Masyarakat, 5(2), 85-92. https://media.neliti.com/media/publications/111297-ID-hubungan-karakteristik-narapidanaprefer.pdf

Damayanti, S. (2014). Hubungan Variasi Menu, Besar Porsi, Sisa Makanan, dan Tingkat Kepuasan Pasien Pada Makanan Lunak Di Rumah Sakit Umum Daerah Cengkareng. Universitas Esa Unggul.

Febrianti, D. (2009). Penyelenggaraan Makanan, Tingkat Konsumsi dan Analisis Preferensi Atlet di SMA Negeri Ragunan Jakarta. Institut Pertanian Bogor.

Hafidz Asy'ari Hasbullah, U., Setiyowati, E., Widiatmi, N., Fauzi Dzulqarnaen, F., Noor, Z., \& Aminah, S. (2017). Sistem Penyelenggaraan Dan Pengelolaan Makanan Bagi Atlet Sepak Bola. Jurnal Jendela Olahraga, 2(1), 148-154. https://doi.org/10.26877/jo.v2i1.1300

Juariah, J. (2007). Faktor-Faktor yang Mempengaruhi Sisa Makanan Biasa pada Pasien Kelas III Rawat Inap di Rumah Sakit Umum Dr. Soedarso Pontianak. Universitas Gadjah Mada.

Kemenkes RI. (2013). Pedoman Gizi Olahraga Atlet. Kementrian Kesehatan RI.

Kustiyoasih, M. P., Adriani, M., \& Nindya, T. S. (2017). Penyelenggaraan Makanan Dan Kepuasan Konsumen Di Kantin Lantai 2 Rumah Sakit Universitas Airlangga Surabaya. Media Gizi Indonesia, 11(1), 11. https://doi.org/10.20473/mgi.v11i1.11-16

Lumbantoruan, D. B. S. (2012). Hubungan Penampilan Makanan dan Faktor Lainnya dengan Sisa Makanan Biasa Pasien Kelas 3 Seruni RS Puri Cinere Depok Bulan April-Mei 2012. Universitas Indonesia.

Moehyi, S. (1992). Penyelenggaraan Makanan Institusi dan Jasa Boga. Bharata.

Nareswara, A. S. (2017). Hubungan Kepuasan Pasien dari Kualitas Makanan Rumah Sakit dengan Sisa Makanan di RSUD Kota Semarang. Ilmu Gizi Indonesia, 01(01), 34-39.

Nurdianty, I., Radhiyah, N., Dachlan, D. M., \& Nawir, N. (2012). Food Management and Satisfaction Level of Athletes in Student Training and Education Center, Department of Education Youth and Sports Makassar. Media Gizi Masyarakat Indonesia, 1(2).

Purba, R. ., Kandou, G., \& Laode, A. C. (2013). Faktor-Faktor Yang Berhubungan Dengan Tingkat Kepuasan Pasien Pada Penyelenggaraan Makanan Di Blu Irina C. Rumah Sakit Umum Pusat Prof. Dr. R. D. Kandou Manado. Universitas Sam Ratulangi Manado

Rotua, M., \& Siregar, R. (2014). Manajemen Sistem Penyelenggaraan Makanan Institusi Dasar. Buku Kedokteran EGC.

Syafrizar, \& Welis, W. (2009). Gizi Olahraga. In Ilmu Gizi:Teori \& Aplikasi. https://doi.org/10.1016/0198-0254(79)90606-X

Tanuwijaya, L. K. dkk. (2019). Kepuasan Pasien Terhadap Variasi Bahan Makanan di Rumah Sakit. 

Jurnal
Gizi,
8 ,
$50-58$.

https://www.researchgate.net/publication/326122173_Sisa_Makanan_Pasien_Rawat_Inap_Analisis_ Kualitatif/download

Wahyunani, B. D. (2017). Hubungan Tingkat Kepuasan Pasien Terhadap Pelayanan Gizi Dengan Sisa Makanan Pasien VIP Di Rumah Sakit Panti Rapih Yogyakarta. Politeknik Kesehatan Kementrian Kesehatan Yogyakarta. 